\title{
Hostel Residents' Knowledge on Feminine Hygiene-Effect of Information Booklet
}

\author{
${ }^{1}$ Department of Child Health Nursing, Nitte Usha Institute of Nursing \\ Sciences, Nitte (Deemed to be University), Mangalore, Karnataka, \\ India \\ 2 Department of Medical Surgical Nursing, Nitte Usha Institute of \\ Nursing Sciences, Nitte (Deemed to be University), Mangalore, \\ Karnataka, India \\ J Health Allied Sci ${ }^{\mathrm{NU}}$ 2022;12:336-340.
}

Jeevitha Alva ${ }^{1}$ Sujatha R. Kannappan ${ }^{10}$ Gincy Joseph ${ }^{2}$ Shivaleela Upashe ${ }^{1}$

\begin{abstract}
Address for correspondence Sujatha. R. Kannappan, Department of Child Health Nursing, Nitte Usha Institute of Nursing Sciences, Nitte (Deemed to be University), Paneer, Derlakatte, Mangalore 575018, Karnataka, India (e-mail: sujatha@nitte.edu.in).
\end{abstract}

\begin{abstract}
Purpose of the Study Adolescence is the transformational period of life from childhood to adulthood. Pubertal changes influence the functioning of the reproductory tract of adolescent girls. At this stage, adequate knowledge of feminine hygiene becomes vital in the prevention of urinary tract infection; if not treated, it may cause various complications in the future. Hence, every adolescent girl needs to be educated on the importance of maintaining femininity.

Methods A quantitative research methodology was adopted, with a one-group preand posttest design. A random sampling procedure was used to find 100 samples that met the inclusion criteria. A structured knowledge questionnaire was used to get the essential data. Following the pretest, an information brochure on feminine hygiene was distributed. After 7 days, a posttest was conducted.

Results The acquired data were analyzed with descriptive and inferential statistics. Around $72 \%$ of the participants were under the age of 18 . Thirty percent of them did not receive any feminine hygiene information. The mean posttest knowledge score of

Keywords

- adolescent

- female

- hygiene

- infection

- pamphlets 16.54 is higher than the pretest knowledge score of 14.31 , indicating that understanding of feminine hygiene has improved.

Conclusion In the pretest, 39\% of hostel residents had poor awareness of feminine hygiene, indicating a need for instruction. The difference in knowledge score between pre- and posttest knowledge demonstrates the usefulness of the information booklet in enhancing feminine hygiene knowledge.
\end{abstract}

\section{Introduction}

Hygiene is a series of practices performed by an individual in day-to-day life to promote a healthy lifestyle. Hygienic practices include the cleanliness of human body. Hygienic practices are most important in adolescent females as it can

published online

November 22, 2021
DOI https://doi.org/ 10.1055/s-0041-1739231. ISSN 2582-4287. affect reproductive health. Women's hygiene is one of the most important elements of hygiene practices. Lack of feminine hygiene increases the risk of developing infections such as candidiasis, reproductive tract infections, and urinary tract infection (UTI). UTI is the frequent infection among females due to differences in the anatomical structure of the

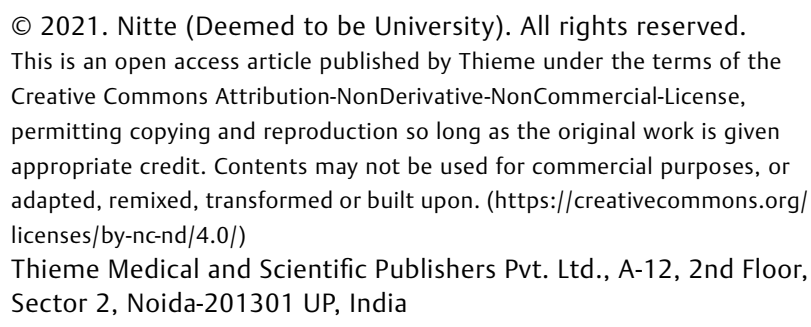


reproductive tract. The health of reproductive system structures must be maintained as a priority for female hygiene.

Moreno ${ }^{1}$ noted that UTIs were three times more common in female adolescents and young women than in young men. UTIs affected $3 \%$ of girls and $1 \%$ of boys aged 11 years. Residents of the hostel can complain of itching, bruising, sniffing discharge, which is often diagnosed as UTI. It often leads to discomfort among teenagers with symptoms such as fever, pain in the lower abdomen, and micturition. ${ }^{2}$

Adolescence is the period of transition from childhood to adulthood. Pubertal, psychophysical maturation, endocrinological, metabolic, somatic, and physiological changes occur during this period. Adolescents in good health secrete small amounts of discharge from the reproductive system, which is a normal physiologic reaction that involves the shedding of cervical and vaginal cells. Irregular cleaning and poor hygiene can promote the growth and spread of bacteria within the genital organs, which can have serious consequences.

A similar research among 177 nursing students revealed that nearly $20 \%$ (35/177) of the nursing females experienced a symptomatic episode in the previous 3 months, with $23 \%$ $(8 / 35)$ being symptomatic at the time of study. Nearly half of the girls $(45.7 \%(16 / 35)$ experienced a single episode in the previous 3 months, and the most frequent clinical presentation indicated by more than half of the girls (57\% (20/35) was frequency with dysuria. ${ }^{3}$

Feminine hygiene is operationalized as the adoption of healthy practices of feminine hygiene and improved knowledge level among the hostel students after the provision of information booklet.

Srivastava ${ }^{4}$ reported $40 \%$ of teens drink less than four glasses of water a day in this survey. Low water intake not only focuses on urine but also results in urinary stasis that promotes bacterial development. Menstrual hygienic practices also contribute to feminine health among adolescent girls. The risk of developing infection and other gynecological problems will be higher in the future due to unhealthy practices. The reproductive tract infection is three times more common among adolescent girls who have poor menstrual hygiene. According to a report published by the Financial Services Guide (FSG), the national momentum in India may immediately be exploited to enhance menstruation health, especially for girls. The priorities include building awarenessraising ability for facilitators, better reach and quality of lowcost pads, and improved influencer targeting. Girls are influenced by broad gender disparities in India and the presence of discriminatory social norms can limit their ability to regulate their menstrual life. ${ }^{5}$ A study found that $71 \%$ of adolescent girls in India do not know about menstrual and menstrual hygiene practices, which clearly shows that lack of knowledge about feminine hygiene. ${ }^{6}$ Adolescents must be educated on the importance of feminine hygiene, which contributes to overall health.

Hygiene practices play a pivotal role in boosting our immune system. Poor hygiene can cause foul-smelling odors and alter the color of genital secretions. Many experience pelvic or vulvar inconvenience, itching, and excessive vaginal discharge during the teenage years. ${ }^{2,3}$ These changes necessitate an immediate assessment, but they refuse to discuss them with others. Hygiene is an important component of health at this time because it aids in infection prevention. If immediate attention is not given, it may result in serious future complications. These infections can be avoided if adolescents are taught proper hygiene practices during their adolescent years.

A similar research on female hygiene practices found that $21.3 \%$ of nurses and $38.9 \%$ of patients had vulvovaginitis. This study shows a significantly lower level of recurring vaginitis among nurses than patients, which stresses the importance of prevention education. ${ }^{7}$

According to one study, $68.3 \%$ of high school adolescent girls had a poor understanding of menstruation and $60.3 \%$ practiced poor menstrual hygiene. Poor menstrual hygiene was found to be associated with longer menstrual flow days (odds ratio $[\mathrm{OR}]=2.51,95 \%$ confidence interval $[\mathrm{CI}]$ : 1.66 , $3.80)$ and lack of understanding of menstruation $(\mathrm{OR}=1.48$, 95\% CI: $1.04,2.1)$. The findings also lend credence to the theory that a lack of information leads to poor menstrual hygiene ${ }^{8}$ This shows a need to construct reasonable conscientiousness-building and advocacy programs for young girls and the general public to increase their menstrual flow understanding and safe health behavior. Based on the above findings, the current study was designed with the goal of determining the effects of an educational booklet on knowledge of feminine hygiene.

\section{Methods}

To achieve the study objectives, the current study used a quantitative approach with a one-group pretest-posttest design. To select 100 participants who met the inclusion and exclusion criteria, a simple random sample procedure was used. The study participants were all female students in their first year of a BSc Nursing, MLT (Medical Laboratory Technology), MIT (Medical Imaging Technology), and AOTT (Anesthesia and Operation Theater Technology) program who live in hostels with similar characteristics. Female students who had previously been exposed to a UTI or who were receiving treatment were excluded from the study. Residents of the hostel were operationalized as students residing in the hostel. The researchers constructed the questionnaire, which was validated by various experts in the field. It is divided into two sections: section $A$, which contains demographic questions; and section $B$, which contains 19 knowledge-based questions about feminine hygiene. The demographic proforma was used to collect the participants' basic information. On the basis of the literature, a complete questionnaire on knowledge of the feminine hygiene needs was developed and validated. The overall score was 19, and based on the median score from the pretest, the score was evaluated as adequate knowledge and inadequate knowledge. Following the pretest, the participants were given a booklet of information to read. After 7 days of intervention, the investigators used the same structured knowledge questionnaire for posttest to assess 
Table 1 Frequency and percentage distribution of knowledge score on feminine hygiene among hostel residents, $n=100$

\begin{tabular}{|c|c|c|c|c|}
\hline \multirow{2}{*}{$\begin{array}{l}\text { Knowledge } \\
\text { on } \\
\text { feminine } \\
\text { hygiene }\end{array}$} & \multicolumn{2}{|l|}{ Pretest } & \multicolumn{2}{|l|}{ Posttest } \\
\hline & $\begin{array}{l}\text { Frequency } \\
\text { (f) }\end{array}$ & $\begin{array}{l}\text { Percentage } \\
\text { (\%) }\end{array}$ & $\begin{array}{l}\text { Frequency } \\
\text { (f) }\end{array}$ & $\begin{array}{l}\text { Percentage } \\
\text { (\%) }\end{array}$ \\
\hline $\begin{array}{l}\text { Adequate } \\
\text { knowledge } \\
(15-19)\end{array}$ & 61 & 61 & 85 & 85 \\
\hline $\begin{array}{l}\text { Inadequate } \\
\text { knowledge } \\
(0-14)\end{array}$ & 39 & 39 & 15 & 15 \\
\hline
\end{tabular}

the level of knowledge about feminine hygiene. SPSS software was used for analysis.

\section{Results}

In this study, $72 \%$ of participants were between the ages of 18 and 19 , while $26 \%$ are between the ages of 19 and 20 . Sixtyseven (67\%) participants were nursing students, eleven (11\%) were AOTT students, twelve (12\%) were MIT students, and ten $(10 \%)$ were MLT students. Seventy percent of students received information, while $30 \%$ had received no information on feminine hygiene prior to the intervention.

Based on the median score of the pretest knowledge, the total scores were interpreted as adequate knowledge (more than 14) and inadequate knowledge (14 and less than 14).

- Table 1 describes the pretest in which $61 \%$ of them had adequate knowledge (score: $15-19$ ) and 39\% had inadequate knowledge (score: $1-14$ ) of feminine hygiene. Following the intervention, $85 \%$ of those tested had adequate knowledge, while $15 \%$ had inadequate knowledge.

In the pretest, $66 \%$ of the participants were unaware of the common causes of UTI, which improved to $80 \%$ in the posttest following intervention. Only 56\% of them expressed common UTI symptoms on the pretest, but knowledge increased to $79 \%$ on the posttest. In the pretest, $59 \%$ of the students knew the $\mathrm{pH}$ of the feminine hygiene product. The knowledge gain in the posttest was $73 \%$.

In the pretest, $\sim 48 \%$ of the students knew the duration of the menstrual cycle. Following the distribution of an information booklet on feminine hygiene, the knowledge level increased to $71 \%$. In the pretest, only $15 \%$ of the students were aware of menstrual hygiene products. After the posttest, the knowledge level increased to $59 \%$. In the pretest, $66 \%$ were aware of the practices to be followed to maintain feminine hygiene. Following the intervention, posttest knowledge increased to $77 \%$. Pretest knowledge of the frequency with which to change sanitary napkins was $71 \%$, and posttest knowledge increased to $96 \%$. In the pretest, $63 \%$ of the students were aware of the direction for cleaning the genital area. In the posttest, knowledge improved to $94 \%$.

- Table 2 shows that the pretest median value for hostel residents' knowledge was 14 , which was lower than the posttest median score of 17 . The Shapiro-Wilk normality test revealed that the data did not follow the normality
Table 2 Effectiveness of information booklet on feminine hygiene on knowledge

\begin{tabular}{|l|l|l|l|l|}
\hline Knowledge & Median & IQR & Z-value & $p$-Value \\
\hline Pretest knowledge & 14 & 3 & -6.321 & $0.000^{\mathrm{a}}$ \\
\cline { 1 - 3 } Posttest knowledge & 17 & 3 & & \\
\hline
\end{tabular}

Abbreviation: IQR, interquartile range.

${ }^{\mathrm{a}}$ Significant.

( $p$-values: 0.000 and 0.000 for pre- and posttest, respectively). As a result, the researchers decided to use the nonparametric Wilcoxon signed-rank test to assess the effectiveness of an information booklet on feminine hygiene knowledge. The calculated $Z$ value is -6.321 , and the calculated $p$-value is 0.000 , which is 0.05 . As a result, it is clear that research hypothesis $\mathrm{H} 1$ (there is a significant difference between preand posttest knowledge among hostel residents) was accepted at a $5 \%$ level of significance.

\section{Discussion}

According to the findings of the current study, the majority of the sample, $72 \%$, were between the ages of 18 and 19 , with only $2.0 \%$ being between the ages of 20 and 21 . A maximum of $67 \%$ of the samples were from nursing, $11 \%$ from AOTT, 12.0 (12.0\%) from MIT, and 10\% from MLT.

A related study on the assessment of UTI knowledge and prevention practices among female students at the University of Jos discovered that $62.5 \%$ of the samples were between the ages of 18 and 22, 27.6\% were first-year students, and $73.7 \%$ lived in the hostel. ${ }^{9}$

The posttest results show that knowledge of feminine hygiene has improved as a result of the information booklet. This denotes repeated training or education will assist students in adopting the necessary practices to improve feminine hygiene.

A comparable study by Padhy et $\mathrm{al}^{10}$ on reproductive health among adolescent girls found that knowledge of the anatomy and physiology of reproduction, reproductive health, and personal hygiene improved significantly after the planned teaching program. The study concludes that a well-organized and systematic planned teaching program will aid in the transmission of knowledge about reproductive health effects to adolescent girls. The authors proposed that the health-care providers teach women about safe and cost-effective healthcare practices during menstruation. Health-care experts train new professionals on the application of good methods for preserving feminine hygiene and pass on their expertise to future generations.

It is our responsibility as health-care professionals to instill appropriate feminine hygienic techniques in students at the start of their professional lives. As a consequence, it promotes a healthy approach by preventing infection of the genital tract. Repeated education in the form of small videos or booklets can be used to aid in the instillation of the routine habit.

In the current study, $66 \%$ of the students were unaware of the most common causes of UTI in the pretest; knowledge 
improved to $80 \%$ in the posttest. In the pretest, $63 \%$ of the students knew which way to clean their genital area. In the pretest, burning sensation is the most frequent symptom of UTI according to $~ 56 \%$ of students. Only $48 \%$ of students knew that the average menstrual cycle lasts 3 to 5 days. Sixty-six percent were aware that feminine cosmetics should not be used to clean the perineal region. Only $15 \%$ of respondents were aware that menstrual cups may be used as a feminine hygiene product during menstruation. Seventyone percent were aware that sanitary napkins should be replaced every 4 hours. Sixty-three percent were confident in their knowledge of how to clean the genital region from front to back.

According to the findings of a study on adult feminine hygienic practices, 101 (52\%) participants always wiped front to back after urination or defecation, whereas 36 women (19\%) never did. Two-thirds ( $n=126 ; 65 \%)$ of the respondents reported always washing their hands after urination or defecation. Ninety-two (48\%) respondents used tampons at all times; 37 (19\%) used sanitary pads. When sanitary pads were used, they were changed constantly at intervals of 6 hours. ${ }^{11}$

Students who are away from home require supervision to maintain their feminine hygiene. The occurrence of UTI due to a variety of factors repeatedly demonstrates the need for students to be educated on a regular basis. Primary education of students at the time of admission to the hostel can aid in the early detection of infection of the reproductive tract, thereby preventing further complications. Thus, it is essential to educate female adolescence on healthier hygienic practices, including menstrual hygiene, on a regular basis.

The study's current findings show that following the intervention, pretest knowledge on the frequency of changing sanitary napkins was $71 \%$, and posttest knowledge improved to $96 \%$. Because students in their first year may face a variety of challenges, including the use of public restrooms or long periods of practical hours, difficulty communicating, language barriers, and anxiety, all of which contribute to the development of UTI, it is critical to teach hostel residents about the duration of changing their sanitary napkin.

In the pretest, $\sim 56 \%$ of them expressed the common symptoms of UTI, whereas posttest knowledge was $79 \%$, indicating improvement after providing the information booklet in the current study. It could be a case of neglect for many of the hostel's residents.

In the pretest, only $15 \%$ of the students were aware of feminine hygiene products. Following the posttest, the knowledge level increased to 59\%. In the pretest, $59 \%$ of the students knew what the $\mathrm{pH}$ of the feminine product was. The posttest knowledge rate was $73 \%$.

Adolescents' exposure to feminine hygiene products is limited due to a variety of factors such as financial considerations, cultural background, parental educational status, lack of availability, insufficient knowledge, and guidance on usage.

The genitourinary tract infections are a key public health concern that affects millions of people every year, especially teens and women. Similarly, in another study, the knowledge of the preventative measures of genitourinary infections ( $n=462$ ) has been improved from 23.8 to $99.4 \%$ following program sessions and improved on the practice of hygiene from 46 to 350 adolescents. $^{12}$

According to Sharma et al, ${ }^{13}$ systematic review and metamenstrual hygiene preparedness among schools in India, teachers are the least common source of menstrual hygiene information for girls (pooled prevalence $=0.07,0.05-0.08$, I $2=100.0 \%, n=86$ ). In 74 research studies, school teachers were also identified as a less prevalent source of menstrual hygiene management knowledge among teenage females. It is crucial for teachers to educate students on feminine hygiene. This helps to prevent further infection-related complications in young females. Infections of the genitourinary tract can be avoided by emphasizing the importance of hygienic practices on a regular basis. Along with adequate knowledge, the approach should be reinforced through repeated education using various audio visual aids. Students in health care, in particular, must be educated not just with adequate information but also with healthy practices to become competent health-care providers in the future.

\section{Conclusion}

According to the current study, $72.0 \%$ of the samples were under the age of $18,67.0 \%$ from nursing, $11.0 \%$ from AOTT, and $12.0 \%$ from MIT, and $10.0 \%$ were from MLT. It should be noted that $30.0 \%$ of the participants did not receive any information about feminine hygiene. It implies that there is still a small proportion of the adolescent female population that requires education on feminine hygiene. The improvement from a pretest score of $61 \%$ knowledgeable and $39 \%$ poor knowledge to a posttest score of $85 \%$ knowledgeable and $15 \%$ poor knowledge indicates the effectiveness of the information booklet in improving menstrual hygiene knowledge. More education is needed to raise awareness about the importance of maintaining feminine hygiene and the practices. One of the most effective ways to sensitize girls in professional colleges is through pamphlets, short videos, and role plays.

\section{Conflict of Interest}

None declared.

\section{Acknowledgment}

The authors of this article would like to express their gratitude to the Nitte (Deemed to be University), for their assistance and support.

\section{References}

1 Moreno MA. Urinary tract infections in children and adolescents. JAMA Pediatr 2016;170(09):916

2 Urinary Tract Infections. Kidshealth.org. Accessed October 14, 2021 at: https://kidshealth.org/en/teens/uti.html

3 Vyas S, Varshney D, Sharma P, Juyal R, Nautiyal V, Shrotriya V. An overview of the predictors of symptomatic urinary tract infection among nursing students. Ann Med Health Sci Res 2015;5(01): $54-58$ 
4 Srivastava S. Analytical study of urinary tract infection in adolescent girls. Int J Reprod Contracept Obstet Gynecol 2018;7(04):1385

5 Menstrual Health in India | Landscape Analysis. Menstrualhygieneday.org. Accessed August 15, 2021 at: https:// menstrualhygieneday.org/wp-content/uploads/2016/04/FSGMenstrual-Health-Landscape_India.pdf

6 Mahon T, Fernandes M. Menstrual hygiene in South Asia: a neglected issue for WASH (water, sanitation and hygiene) programmes. Gend Dev 2010;18(01):99-113

7 Attieh E, Maalouf S, Roumieh D, Abdayem P, AbiTayeh G, Kesrouani $A$. Feminine hygiene practices among female patients and nurses in Lebanon. Reprod Health 2016;13(01):59

8 Belayneh Z, Mekuriaw B. Knowledge and menstrual hygiene practice among adolescent school girls in southern Ethiopia: a cross-sectional study. BMC Public Health 2019;19(01):1595

9 Mangai M, Gaknung B, Hosea G, et al. Assessment of knowledge and prevention practices of urinary tract infection (UTI) among female students residence in university of Jos. Int Res J Public and Environ Health Published August 2019. Accessed October 14, 2021 at: https://journalissues.org/wp-content/uploads/2019/08/ Mafuyai-et-al.pdf

10 Padhy GK, Pattanayak A, Jena D. Effectiveness of planned teaching programme on reproductive health among adolescent girls. Indian Medical Gazette Published online 2013. Accessed October 14, 2021 at: https://imsear.searo.who.int/handle/123456789/157534

11 Czerwinski BS. Adult feminine hygiene practices. Appl Nurs Res 1996;9(03):123-129

12 Al-Kotb H, Elbahnasawy HT, El Nagar SA, Ghabyen NS. Prevention for genitourinary tract infection among female adolescents students. IOSR J Nurs Health Sci 2016;05(04):12-18

13 Sharma S, Mehra D, Brusselaers N, Mehra S. Menstrual hygiene preparedness among schools in India: a systematic review and meta-analysis of system-and policy-level actions. Int J Environ Res Public Health 2020;17(02):647 